G.I.N. Rozvany • O.M. Querin - Z. Gaspar • V. Pomezanski

\title{
Erratum for the Brief Note "Extended optimality in topology design" by G.I.N. Rozvany, O.M. Querin, Z. Gaspar, V. Pomezanski, (SMO 24, 257-261, 2002)
}

Received: 15 June 2005 / Published online: 12 September 2005

(C) Springer-Verlag 2005

On page 258 , in equation (3)

"min/max $C / f$ (respectively, for prescribed loads/displacements" should read

"min $C f / \max C / f$ (respectively for prescribed loads/displacements)"

(the expression $C f$ was omitted in the typesetting).

Since the sign "/" is used for two different meanings, a clearer statement would be

"min $C f$ and $\max C / f$ (respectively, for prescribed loads and displacements)"
On page 258, before Sub-section 4.1

Add

"In the examples, we use zero Poisson's ratio for simplicity, but similar results are obtained with non-zero Poisson's ratios."

The online version of the original article can be found at:

http://dx.doi.org/10.1007/s00158-002-0235-x

G.I.N. Rozvany $(\bowtie)$ · Z. Gaspar · V. Pomezanski

Research Group for Computational Structural Mechanics, Hungarian Academy of Sciences and Budapest University of Technology and Economics, Müegyetem rkpt. 3, Kmf. 35, 1521 Budapest, Hungary

E-mail: rozvany@eik.bme.hu

O.M. Querin

School of Mechanical Engineering, The University of Leeds, Leeds, LS2 9JT, United Kingdom

E-mail: ozz@mech-eng.leeds.ac.uk 